\title{
Assessment of Barriers and Opportunities for Renewable Energy Development in Chile
}

\author{
Shahriyar Nasirov ${ }^{1}$, Carlos Silva ${ }^{1}$ and Claudio A. Agostini ${ }^{2}$
}

\begin{abstract}
:
Chile has become increasingly dependent on energy imports and its energy demand has grown exponentially in the past decade, impacting the environment and the production costs in the economy. In fact, electricity prices have doubled and it is expected that they will soar in the next decade if Chile does not find a solution for its dependence from imported energy resources. Recent developments, particularly improvements in the regulatory framework and incentives for renewables, have accelerated the growth process and investment opportunities of Renewable Energy Technologies (RETs). However, RETs have faced a number of constraints affecting their penetration. In this paper, we review the existing opportunities and also identify and rank the major barrier categories for the development of RETs in the Chilean context. For this purpose, the Analytical Hierarchy Process (AHP) technique has been utilized for ranking the barriers based on experts' opinions (selected from academia and industry).
\end{abstract}

Keywords: Renewables; Energy; Policies; Chile; Barriers

\footnotetext{
${ }^{1}$ Facultad de Ingeniería y Ciencias, Universidad Adolfo Ibáñez, Avenida Diagonal Las Torres 2640, Peñalolén, Santiago 7941169, Chile; Email: c.silva@uai.cl (C.S.);

2 School of Government, Universidad Adolfo Ibañez, Avenida Diagonal Las Torres 2640, Peñalolén, Santiago 7941169, Chile; Email: claudio.agostini@uai.cl (C.A)

* Author to whom correspondence should be addressed; E-Mail: shahriyar.nasirov@uai.cl; Tel.: +56-2-2331-1777. Fax: +56-2-2331-1777.
} 


\section{Introduction:}

Over the past decade, Chile has become one of South America's most stable economy thanks to its structural reforms, open market-driven policies, and structural fiscal surplus rule. The Global Competitiveness Report for 2014-2015 ranks Chile among the most competitive countries in the world $-33^{\text {rd }}$ place in the global ranking- and the top one in South America, well ahead of the closest South American countries (México (61), Peru (65), Colombia (66), Brazil (57)) (Reference). At the same time, it has reached a level of economic development that has challenged the energy sector due to a significant growth in energy demand. However, over the previous decades, the Chilean government failed to provide a stable regulatory framework that would encourage sufficient investment in the energy sector to keep pace with economic growth. As a consequence, the energy sector has suffered from various severe crises, including blackout periods (References).

Unlike many of its South American neighbours, Chile has no domestic fossil energy resources. Yet, imported fossil resources: coal, diesel, and liquefied natural gas (GNL) account for almost $70 \%$ of the country's total energy consumption (Reference). Therefore, the mix of a growing energy demand, increasing dependence on imported energy sources, and rising costs of fossil fuel prices have led to skyrocketing electricity costs for both households and industries. The electricity prices have doubled in the past 7 years and it is expected that they will soar another $35 \%$ in the next decade if Chile does not find a solution for its dependence on imported energy (Reference). High energy cost, shortages and blackouts are key challenges for Chile's private sector. The problem is especially serious for the mining industry in which the cost of energy now represents about $20-30 \%$ of the total cost of production. The effect on the country is also significant, as the mining industry accounts for $20 \%$ of GDP and $60 \%$ of exports, 
and is already paying twice as much for electricity as mining industry in Peru. While Chile's mining industry is not thriving as before, its demand for energy is expected to continue to grow at a rate of at least $5 \%$ annually for the next several years. According to projections of the National Energy Commission (CNE), $60 \%$ of new electrical demand in the country will come from the mining sector (Reference). In order to avoid another energy crisis associated with further cost increases, Chile urgently needs to attract new generation projects for the diversification of its energy sources.

As a result, the Chilean government has recently scaled-up its efforts to push for energy diversification as an essential feature of the country's energy policy. To advance in this matter, the government has focused on determining what energy sources and technologies need to be prioritized to provide energy security and environmental sustainability at a competitive cost.

Since large hydro development has slowed down due to social and environmental conflicts, the development of Renewable Energy Sources (RES) is positioning itself as a good source of clean and competitive energy, which can have a major impact on the future energy diversification of the country (Reference). Chile has enormous renewable energy potential but it is underperforming with regard to its use both for electricity production and heating. In this context, the paper analyses the incentives for the promotion of renewable energy technologies (RETs) that support sustainable development and the barriers that still remain as a big challenge to investors involved in implementing these technologies in Chile. The rest of the paper is organized as follows: Section 2 reviews the renewable energy resources potential and the policy incentives to RES deployment. Section 3 describes RETs in Chile and their status; Section 4 outlines the methodology of Analytic Hierarchy Process (AHP) to identify key barrier categories 
to RES development; Section 5 presents results and discussions; and finally, Section 6 concludes with policy recommendations.

\section{Review of RES potential and Policy incentives}

Chile is considered one of the most attractive countries for the development of RETs, mostly because its geographic location and diversity provides abundant renewable energy resources. Particularly, a significant potential in biomass, hydropower, geothermal, solar, wave and wind have not been exploited yet (References). There are over 4000 miles of windy coastline, which might be excellent conditions to boost wave and wind energy. The wind-resource potential of Chile may reach 40,000 MW, according to preliminary estimations. Chile has over 15 percent of the world`s active and dormant volcanoes and more than 300 geothermal areas have been identified to develop geothermal energy. Among the RES, the development of solar energy in Chile is particularly attractive as the country is endowed with one of the largest solar potentials in the world (References). The Atacama Desert (one of the world's driest desert), in northern Chile, offers the best conditions for generating solar energy with up to $9.28 \mathrm{KWh}$ of sunlight daily, among the world's highest.

\subsection{Policy Incentives}

The classification of non-conventional renewable generation sources in Chile was formally defined, for legal and regulatory purposes, for the first time in 2008 by the Law No 20,257 and includes the following: biomass, small hydraulic energy (maximum capacity is less than 20MW), geothermal energy, solar energy, wind power and energy of sea including all forms of mechanical energy produced by the movement of tides, waves and currents, as well as that obtained from the thermal gradient of the seas (Reference). The Law No 20,257 establishes a Renewable Portfolio Standard (RPS) that creates the obligation for generators to incorporate a minimum percentage of electricity 
from RES into their energy mix. One of the key provisions of the law states that every generator who buys energy in the spot market and has installed capacity greater than 200 MW to sell to distributors or final consumers, must guarantee $10 \%$ of its purchases from RETs within each calendar year. Lately in 2013, the Chilean government amended the Law by doubling its renewable-energy target from the previous goal of $10 \%$ by 2024 to $20 \%$ by 2025 . The minimum legal percentage is $5 \%$ for the years 2010 through 2014 and then increases gradually from 2015 based on the date of the contract. For contracts signed between August 31, 2007, and July 1, 2013, the target for generators is to reach a $10 \%$ obligation of their supply from RES by 2024 ; and for contracts signed after July 1, 2013, the aim is to reach a target of $20 \%$ in 2025 .

In order to encourage and facilitate the entrance of new actors with renewable energy generation into the system, Chilean government modified the General Law of Electricity Services (Degree 238/1982) to enable residential end-users with renewables or efficient co-generation facilities to inject excess energy into the grid. This new regulatory framework was approved under a "net billing" Law No 20.571 in 2014 . The law allows households and businesses to install a PV system up to $100 \mathrm{~kW}$ so they can generate electricity for their own use and to sell the system's excess output to the national grid at a fixed tariff. As part of a complimentary legislation with the objective of encouraging a shift to the use of clean technologies, the congress introduced South America's first carbon tax in 2014. The first step will be measuring carbon dioxide emissions from thermal power plants in 2017 and then it will follow a tax on CO2 emissions of power plants in 2018 .

\section{RETs in Chile and their status}

So far, energy generation from RES has met or even surpassed the quota defined by the Renewable Law No 20,257. Since the approval of the law, the installed power capacity 
in renewable energy has increased greatly from $470 \mathrm{MW}$ in 2008 to $2117 \mathrm{MW}$ in 2015 (See Table 1). As of the first quarter of 2015, electricity generation form RES reached $12 \%$ of the total power capacity in the system. Wind power leads the RES installed capacity with $832 \mathrm{MW}$, representing $40 \%$ of the share of renewables in the country. The rest of renewable technologies under operation are distributed as follows: $22 \%$ biotechnologies (465MW), 22\% PV solar (452 MW) and 16\% small hydro (368 MW).

Table 1. The status of renewable energy projects in Chile in 2015 (MW)

\begin{tabular}{ccccc}
\hline Technology & Operating & $\begin{array}{c}\text { Under } \\
\text { construction }\end{array}$ & $\begin{array}{c}\text { Approved } \\
\text { SEIA }\end{array}$ & $\begin{array}{c}\text { Under } \\
\text { Evaluation }\end{array}$ \\
SIC+ SING & & & & \\
\hline Small Hydro & 368 & 57 & 337 & 215 \\
\hline Solar PV & 452 & 748 & 8173 & 4792 \\
\hline Solar CSP & 0 & 110 & 760 & 370 \\
\hline Biomass & 422 & 0 & 134 & 69 \\
\hline Biogas & 43 & 0 & 1 & 8 \\
\hline Wind & 832 & 165 & 5513 & 1960 \\
\hline Geothermal & 0 & 0 & 120 & 0 \\
\hline TOTAL & $\mathbf{2 1 1 7}$ & $\mathbf{1 0 8 0}$ & $\mathbf{1 4 5 5 5}$ & $\mathbf{7 4 1 3}$ \\
\hline
\end{tabular}

Sources: (Reference) and own construction

Chile's renewable sector received $\$ 1.4$ billion in investment in 2014 - a 7\% increase from 2013, reaching an accumulated investment of around $\$ 7.1 \mathrm{bn}$. As a result, the country became the second largest market, after Brazil, for renewable energy investment in the South American region in 2014. Apart from the key incentives mentioned in Section 2, the investment flows to Chile's renewable sector was partly derived by the government's message on upcoming long-term power purchase agreement (PPAs) tenders. The government's plans include to award long-term power purchase agreements (PPAs) tenders between 2015 and 2017 to supply a total of 24,500 GWh to distributors. It is expected that PPAs tenders will provide further certainty to power generators looking to invest in Chile, converting the country in one of the most 
attractive destinations for renewable energy development in South America over the coming decade.

\section{Methodology}

Although a tremendous increase in renewable energy investments has occurred in Chile during a short period of time, still the country remains far from exploiting its full renewable energy potential to meet its increasing energy demand. Despite the favorable conditions and the government goals, the energy sector faces a multitude of crosscutting barriers preventing the implementation of renewable projects on even more significant numbers. As a matter of fact, renewable energy projects with environmental approval reached $21,968 \mathrm{MW}$ in 2014 , but less than $10 \%$ of the capacity of these projects (2117 MW) has materialized to date (See Table 1).

The methodology utilized for identifying key barrier categories in Chile is based on questionnaire survey (comprising quantitative and qualitative data collection) using the Analytic Hierarchy Process (AHP) method. The methodologies already used by Bhatt et al. (2010) and Luthra et al. (2015) provided the basis for our survey design. Luthra (2015) identified the major barriers to RET adoption in India using a methodology similar to the one used in this paper. Using the AHP method, we aimed to prioritize broad dimensions of barriers preventing a large penetration of RETs in the Chilean context. In addition to the data collection from the online questionnaire, several face-toface complementary interviews were conducted. The purpose of these interviews was to obtain important insights based on experts `extended opinions and detailed experiences on the barriers they have faced in the marketplace.

\subsection{Analytic Hierarchy Process (AHP) method}

The AHP is a method to solve decision-making problems by prioritization of alternatives using eigenvectors and manipulation in matrix algebra (Reference). It 
compares alternatives with respect to a pair-wise mode and helps the decision maker to compare and rank the alternatives in making a choice. The AHP method has been applied to numerous decision problems in the field of energy policy where it provides sufficient statistical power to detect group differences or to investigate trait or characteristics of a certain subgroup. It is widely applicable due to its simplicity, ease of use and flexibility (References). Another advantage of using the AHP method is that it provides the possibility of evaluating quantitative as well as qualitative criteria. Despite the popularity of the AHP, many authors have expressed their concerns over certain issues of the methodology. Belton (1986) and Belton and Gear (1997) have long observed some cases in which ranking irregularities can occur when the AHP or some of its variants are used. Another important drawback of the AHP method is the artificial limitation in the use of the numerical scale. Lootsma (1989), for example, argued that the geometric scale is preferable to the numerical scale.

The application of the AHP in our research was split into three phases. In the first phase, the questionnaire was developed for conducting an online survey of experts' opinions (selected from academy and industry) concerning the barriers from broad dimensions to the RETs in Chile. For this purpose, barriers were grouped into six broad categories based on their main characteristics and an extensive literature review (References). These categories included (i) financial and economic (ii) technical and infrastructure (iii) market (iv) regulatory and institutional (v) awareness and information, and (vi) cultural and social. The second phase consisted of establishing the hierarchical structures on which experts are requested to make short pair-wise comparisons between barrier dimensions using a nine-point scale. The rates were from “9”, meaning "extreme importance", to "1", meaning "equal importance". 
At the beginning of the survey, respondents were provided with background information about the aim of the research, the structure of the survey and the selection of barrier categories in detailed. In addition, the respondents were given an option to record their comments and opinions regarding any rated barrier category. The identified barrier dimensions have been then converted into three level hierarchical processes where Level 1 sets the goal, Level 2 represents the priority of the identified six barrier categories and Level 3 contains the overall ranking of barrier dimensions in the Chilean context. Finally, pair-wise comparisons of the different barrier dimensions were converted into comparison matrices in the third phase. These comparisons matrices have been solved with the AHP methodology to determine priority barrier dimensions in the market. To ensure that the determined priorities are statistically consistent, and a consistency check is applied in the final phase. In order to do this, Saaty (1977) has proposed a consistency index $(\mathrm{CI})$, which is related to the eigenvalue method using Eq.(1)

$$
C I=\frac{\tau_{\max }-n}{n-1}
$$

where $\tau_{\max }=$ maximal eigenvalue

Based on the $C I$ and Random Consistency index $(R I)$ the consistency ratio $(C R)$ is calculated using Eq.(2). The consistency ratio, the ratio of CI and RI, is given by:

$$
C R=\frac{C I}{R I}
$$

If $\mathrm{CR}$ is smaller or equal than 10 per cent, then the matrix can be considered as having an acceptable consistency.

\section{Results and discussions}


Based on the rankings obtained through the online questionnaire by experts, the priorities are synthesized using the methodology of AHP. Six categorized dimensions (Technical, Regulatory and Institutional, Financial and Economic, Market, Cultural and Social and Awareness and Information Issues) have been revised for hierarchy. Table 2 shows the weights determined by the experts to these dimensions together with the priority matrix. Based upon overall weights of the barrier dimensions, the ranking of dimensions to adopt RETs in Chile have been made.

Table 2: Ranking of dimensions to RETs adoption

\begin{tabular}{lcccccccc}
\hline $\begin{array}{l}\text { Barrier dimension } \\
\text { categories }\end{array}$ & T & RI & FE & M & CS & AI & $\begin{array}{c}\text { Priority } \\
\text { weighting }\end{array}$ & Rank \\
\hline Technological \& Infrastructure & 1 & 0.50 & 2.00 & 3.00 & 3.00 & 4.00 & $23.3 \%$ & $\mathbf{2}$ \\
Regulatory \& Institutional & 2.00 & 1 & 3.00 & 4.00 & 6.00 & 7.00 & $40.3 \%$ & $\mathbf{1}$ \\
Financial \& Economic & 0.50 & 0.33 & 1 & 2.00 & 3.00 & 2.00 & $14.7 \%$ & $\mathbf{3}$ \\
Market & 0.33 & 0.25 & 0.50 & 1 & 2.00 & 2.00 & $9.6 \%$ & $\mathbf{4}$ \\
Cultural \& Social & 0.33 & 0.17 & 0.33 & 0.50 & 1 & 2.00 & $6.8 \%$ & $\mathbf{5}$ \\
Awareness \& Information & 0.25 & 0.14 & 0.50 & 0.25 & 0.50 & 1 & $5.3 \%$ & $\mathbf{6}$ \\
\hline
\end{tabular}

Maximum Eigenvalue $=6.131$

Consistency Ratio CR $=2.1 \%$

From the analytical results presented in Table 2, "Regulatory and Institutional (40.3\%) " has been reported as the most important dimension of barriers to adopt RETs in Chile. This is followed by "Technical (23.3\%) ", "Financial and Economic (14.7\%) ", " Market $(9.6 \%) ", "$ Cultural and Social (6.8\%) ", and "Awareness and Information (5.3\%).

The following subsections set out the taxonomy of barriers to RETs in Chile. This framework provides a more detailed discussion of the dimensions from the face-to-face interviews with experts selected from a survey where we gathered data on their extended opinions and experiences over the barriers they faced. The aim is to test each claim through the analysis of survey data of various barrier categories. The results of these case studies are discussed using a reduced list of barriers. The following 
subsections include an analysis of the two principal barrier categories that come first in the ranking.

\subsection{Regulatory and Institutional Barriers}

As the majority of respondents confirmed, regulatory and institutional issues are considered to be a major concern restricting a better penetration of RETs in Chile, which is ranked first in the overall ranking of the key barrier categories included in the questionnaire. In the opinion of the interviewees, many of the RETs in Chile are still in the development stage because there are no sufficient regulation and institutional support to stimulate the adoption of these technologies by businesses and industries. Among them, the lack of legal basis and clear procedures to obtain rights-of-way for transmission and distribution lines present significant limitations. Obstacles of property owners' opposition, severe opposition from local communities due to environmental reasons also have a negative impact on investment together with the risk of not reaching an economic agreement due to long delays and uncertainty of incurring in additional costs. An effective open access policy to transmission and non-discriminatory transmission pricing are further critical issues experienced by renewable energy projects in Chile. The existing regulation does not facilitate open access under public transmission system (trunk, sub-transmission and additional systems) and usually results in indefinite delays for new entrants. On the transmission pricing side, the regulatory framework allocates transmission payments to generators based on line usage over time. The expansion of renewable projects may push large parts of the grid to the limit of its abilities due to its intermittent and unpredictability characteristics and can raise transmission tolls. As a result, existing conventional generators oppose new expansion projects because of the increasing transmission toll payments associated to the entrance of renewables. 
Besides, excessive bureaucratic obstacles, non-transparent administrative procedures, with lengthy, complex and cumbersome authorization procedures and lack of coordination between the various authorities have also been raised as key obstacles that are included in the category of regulatory and institutional barriers in Chile.

\subsection{Technical and infrastructure barriers:}

The barriers associated with technical and infrastructure matters have also been highlighted by respondents as the one of the leading obstacles for the development of RES in Chile. As seen from Table 1, this barrier category is positioned in second place in the ranking of the survey results. Respondents noted that limited grid infrastructure in the areas where renewable resources are most abundant presents a current and future barrier to increased generation from RES. Besides, uncertainties regarding the available data and information are among the key obstacles in this category of barriers. Although Chile possesses one of the highest renewable energy resource potentials in the world, a mapping of this potential with an overview of the existing and publicly available resource assessments across the country's regions is still missing. There is a need for detailed information for specific terrain features, land-use exclusions, accessibility to the existing transmission grid and publicly available assessments for further penetration of RES. On the other side, the entrance of RES to the electricity systems can cause powerquality challenges in terms of voltage fluctuation, reactive power compensation, harmonic distortion, energy storage, load demand management, and synchronization because of their intermittence characteristics. Therefore, technical solutions for optimal balancing of energy systems require a high level of technical bases for the technological assessment. The Chilean grid system was primarily designed for conventional energy sources and technologies and there is an insufficient level of technical bases, in many 
cases even virtually non-existent, to evaluate RES. This restriction makes integration of RES much slower.

\section{Conclusions and Policy Recommendations}

Over recent years, policy incentives show good promise in providing a coherent framework that can significantly increased the share of renewable energy within the electricity system and drive the development of renewable technologies in Chile. As a result,, there has been a significant interest in RES and the accumulated investment in this sector has reached its record level in the region. Despite the favorable conditions, the energy sector in Chile faces a multitude of cross-cutting barriers preventing the implementation of renewable projects on even more significant numbers. The paper presents the most important barrier categories identified from a survey and follow-up interviews conducted among experts in Chile. The analysis of the results showed that the top three barriers ranked by the degree of importance given by the interviewees are "regulatory and institutional", "technical and infrastructure", and "financial and economic" matters. Chile faces then the formidable task of removing the identified barriers and creating further incentives for the development of a major renewable energy sector.

In this regard, it is clear that the Chilean government's role will be inevitable. The government should take a leadership role establishing a prioritized strategy to develop and modernize institutional structures to truly integrate public policies and improve the quality of the interactions among an important set of organizations, institutions and public policies. In order to ensure policy viability, the government should intervene directly through the implementation of some development tools. Among the development instruments that could be used are: increasing the level of public funding 
to the sector, government's engagements in offering loan guarantees or issuing "green bonds", taxes on the use of fossil fuels, incentives to the penetration of cleaner sources or to encourage a more efficient use of energy, and explicit environmentally oriented objectives. Integrated resource planning has to be built to coordinate the siting of new power plants and the expansion of transmission and distribution networks. In addition, establishing a comprehensive national transmission planning process, creating standard interconnection procedures, regulating and enforcing open access to transmission networks, strengthening pricing for transmission, are the most urgent measures to be taken.

With respect to the need for technical solutions to manage the intermittency of renewable energy sources, it is required a significant investment in modernizing the grid conditions to adopt the technical requirements of a modern electricity system, including supply and demand side management. To date, in Chile, the Technical Regulation of Security and Quality of Service, which was enacted in 2005, provides certain requirements only for wind technology (Reference). However, there is not a technical regulation for the expected entrance of a significant amount of other renewable technologies in the near future. Therefore, it is important to establish technical regulation procedures for each potential new technology to guarantee grid and load management at all grid levels. 